\title{
Un paseo poliédrico con Rosalía de Castro por Santiago de Compostela
}

\author{
Lucía GARCÍA VEGA \\ Investigadora independiente \\ lugarvega@gmail.com
}

Recibido: $22 / 08 / 2014$

Modificado: $28 / 11 / 2014$

Aceptado: 09/12/2014

\section{Resumen}

El objetivo fundamental de este artículo es abrir nuevas vías de interpretación sobre algunos aspectos espaciales relacionados con el poema "Santa Escolástica" de En las orillas del Sar (1884), última obra publicada en vida de Rosalía de Castro (1837-1885).

Palabras clave: Rosalía de Castro, espacio urbano, Santiago de Compostela, geometría, Platón, mística.

Title: A polyhedral walk with Rosalía de Castro in Santiago de Compostela Abstract

The main objective of this article is to open new avenues of interpretation of some spatial aspects of the poem "Santa Escolástica" of En las orillas del Sar (1884), the last work published in her lifetime of Rosalía de Castro (1837-1885).

Keywords: Rosalía de Castro, urban space, Santiago de Compostela, geometry, Plato, mysticism.

\section{Índice}

1. Introducción

2. Estética hexaédrica del espacio

3. Estética tetraédrica de la luz

4. Conclusiones 


\section{Introducción}

En 2014 se han cumplido 130 años de la publicación de En las orillas del Sar, texto lírico que cerraba la producción literaria de Rosalía de Castro, veintisiete años después de haberse iniciado con la edición de la también obra poética La flor (1857).

Nuestra finalidad aquí es realizar un simbólico paseo estético a través de algunas arquitecturas compostelanas representativas, sobre las que se asienta espacialmente el poema "Santa Escolástica". Compuesto de cuatro partes, las tres primeras secciones semejan ser, a un nivel apriorístico, proclives a (re)descubrir la estética del espacio de Santiago de Compostela, en general, y, en particular, de los espacios arquitectónicos exteriores de cuatro edificios emblemáticos vistos y vividos por Rosalía.

Asimismo, nos proponemos reflexionar acerca de las posibles interpretaciones que la propia seclusión de la poeta propicia, dando pie a avanzar ya no solo por el espacio arquitectónico interior del edificio que alberga la referida imagen de santa Escolástica ${ }^{1}$ y que da título al poema, sino también por las silenciosas naves abisales del templo rosaliano. Esta circunstancia permitiría, tal vez, (re)leer estos versos desde perspectivas nuevas, alguna no muy alejada de la conocida como estética de la luz.

Hasta el momento, el hecho evidente de estar empleando en estos planteamientos alguna voz de la familia léxica de la estética, ya estaría indicando, en buena medida, la dirección que nuestros pasos seguirán durante este trayecto. Según la Real Academia de la Lengua Española, belleza es la propiedad de las cosas que hace amarlas, infundiendo en nosotros deleite espiritual. Esta propiedad existe en la naturaleza y en las obras literarias y artísticas. Define, igualmente, la belleza artística como la que se produce de modo cabal y conforme a los principios estéticos, por intuición de la naturaleza o por intuición del espíritu. Y la belleza ideal, principalmente entre los estéticos platónicos, prototipo, modelo o ejemplar de belleza, que sirve de norma al artista en sus creaciones.

\footnotetext{
${ }^{1}$ Obra del escultor José Ferreiro Suárez (1738-1830). Se estima que el retablo fue realizado entre 1773 y 1777 . A este respecto, vid. López Vázquez $(1990,2009)$ o Bouza Álvarez (1972). Advertimos ya que no es nuestro propósito realizar una interpretación del monumento escultórico en esta ocasión. Debe entenderse, por tanto, que las vías analíticas elegidas en este caso puntual tienen que ver con el espacio arquitectónico en el que se halla.
} 


\section{Estética hexaédrica del espacio}

A principios del siglo XII, el monje cluniacense Aimeric Picaud acompañó en peregrinación a Santiago de Compostela al que, más tarde, se convertiría en la máxima autoridad de la iglesia Católica, el papá Calixto II. Aquel viaje serviría para escribir el Liber Sancti Iacobi, también conocido como Codex Calixtinus, por ser precisamente Calixto II el propulsor de dicha obra. En su libro V, considerado la primera guía del peregrino, Picaud situaba esta ciudad y su popular Catedral de la forma siguiente:

Entre dos ríos, uno de los cuales se llama el Sar y el otro Sarela, está situada la ciudad de Compostela. El Sar está al oriente, entre el Monte del Gozo y la ciudad; el Sarela está al Poniente [...].

En esta ciudad suelen contarse diez iglesias, entre las que brilla gloriosa la primera la del gloriosísimo apóstol Santiago el de Zebedeo, situada en medio [...]; la cuarta, la de San Martín obispo, llamada de Pinario, que también es abadía de monjes. (Picaud 2004: 135)

Extraeremos dos datos de las líneas anteriores. El primero hace referencia a uno de los ríos, el Sar, pues forma parte indisoluble del título En las orillas del Sar. Según el crítico Fermín Bouza Brey, Rosalía habría escrito el poema "Santa Escolástica" mientras vivía en la ciudad compostelana, dando como posible solución cronológica el intervalo comprendido entre 1875 y 1880 (Bouza Brey 1962). En cuanto al segundo, se ofrece como un punto de referencia espacial para el desarrollo de este epígrafe, pues el itinerario seguido nos sitúa en el centro de la vieja Compostela, en la urbs quadrata.

En un trabajo anterior, ya proporcionábamos una detallada explicación acerca de la complicada $y$, a veces, contradictoria convivencia de la conocida escritora romántica ${ }^{2}$ con su ciudad natal, es decir, Santiago de Compostela. Se vislumbraban, entonces, ciertos rasgos empedoclianos ${ }^{3}$ que, por más que se quiera aducir que son licencias poéticas, resultan obvios en un contexto sintáctico extremadamente translúcido como resulta ser, por ejemplo, "Ciudad extraña, hermosa y fea a un tiempo, / a un tiempo apetecida y detestada, / cual ser que nos atrae y nos desdeña" (Castro 1993: 2, 516). De tal manera, un razonamiento generalista acerca de la observación lírica (y también narrativa) de Compostela que realiza Rosalía de Castro, nos emplazaría a admitir preceptivamente la acción de un binomio afinidad-antipatía (García Vega 2011).

\footnotetext{
2 Por cronología, del Romanticismo tardío.

${ }^{3}$ Empédocles (ca. 490 a.C.-435 a.C.) fue un político, filósofo y poeta griego. En su tratado de la formación del mundo, defiende la existencia de cuatro elementos (agua, aire, tierra y fuego), sobre los que actuarían dos fuerzas activas y opuestas, el amor y el odio, que determinarían todo en el universo.
} 
De las cuatro partes que constituyen "Santa Escolástica", en este epígrafe nos centraremos en el itinerario artístico que la escritora sigue a través de los sextetos de endecasílabos sin rima de las tres primeras partes del texto, lo que, quizá, habilitaría para acometer una reflexión filosófica en base a los juicios estéticos filtrados por las vetas del verso.

La poeta inicia su deambular físico en un punto indefinido de la ciudad, un recorrido que realiza sola, sin tan siquiera aceptar la compañía de su genuino símbolo personal, esto es, su sombra. Parece aspirar a alcanzar un estado de incomunicación e interiorización: "desiertas calles", "mundo sin piedad desierto", "no hay rumores" (Castro 1993: 2, 514). Su visión de Compostela es la de un "sepulcro", por tanto, de una construcción erguida sobre el suelo que la cubre o, si se prefiere, encierra dentro de un espacio sensorial cercano, en su forma, a uno de los conocidos como sólidos platónicos; nos referimos al hexaedro o cubo.

Siguiendo la ruta que nos impone la estética hexaédrica, advertimos que el demiurgo creador de "Santa Escolástica" nos guía a través de cuatro arquitecturas compostelanas, las cuales, de una u otra manera, parecen adecuarse a ser vistas y vividas en base a una contemplación espacial poligonal del cuadrado y a una percepción volumétrica poliédrica del hexaedro.

La primera de ellas es el Colegio de Fonseca (en gallego, Colexio de Fonseca), un lugar al que alude como "airosa puerta de Fonseca, muda" (Castro 1993: 2, 514). Este edificio data del siglo XVI, levantado sobre una planta cuadrada. Su fachada consta de dos cuerpos, jalonados por dos columnas a ambos lados, es decir, cuatro columnas en el primer cuerpo y otras cuatro en el segundo cuerpo. Es comúnmente aceptado que esta portada renacentista representa la sabiduría cristiana. En el poema, Rosalía hace mención a las "estatuas y relieves / primorosos, encanto del artista" (Castro 1993: $2,514)$, esto es, las cuatro figuras situadas en los intercolumnios, que se corresponden con Santiago Alfeo, san Pedro, san Pablo, san Isidoro y san Leandro. También se encuentra la Virgen de la Sabiduría en este retablo pétreo.

La segunda arquitectura poetizada se corresponde con el Hospital Real. Se refiere a este espacio como "el gran Hospital, la incomparable / obra del genio, ante mis tristes ojos / en el espacio dibujóse altiva" (Castro 1993: 2, 514-515). La construcción del edificio se llevó a cabo en el siglo XVI, proyectada sobre un plano asequible en espacio y volumen: cuatro claustros en torno a una iglesia. Siguiendo los gustos de la época, la portada está dispuesta como el trazado de un retablo. Formada por tres cuerpos, la visión vertical de conjunto nos permite apreciar, a ambos lados izquierdo y derecho, cuatro figuras de bulto redondo entre las dobles pilastras. A la izquierda, de abajo a arriba, son identificables las figuras de Adán, 
santa Catalina, san Juan Bautista y Cristo. Al lado opuesto, también mirando de la parte inferior a la superior, están ubicadas las formas escultóricas de Eva, santa Lucía, María Magdalena y la Virgen con el Niño.

En cuanto a una visión horizontal de la fachada, el segundo cuerpo posee un amplio friso decorado con las representaciones de los doce apóstoles. Ya en el tercer cuerpo, reconocemos otras cuatro figuras, las de Santiago y san Pedro, al lado izquierdo, y las de san Juan y san Pablo, a la derecha.

La tercera construcción objeto de nuestra exposición es el auténtico emblema urbano compostelano e icono de la cristiandad, la Catedral, "sanctasanctórum no espacio interno da cidade" (Davies 1997: 518). En esta ocasión, la poeta la menciona como "palacio místico / de atrevidas románicas arcadas" (Castro 1993: 2, 515), registrando la gran obra del maestro Mateo, por tanto, el pórtico románico "con su Gloria de bellezas llena" (Castro 1993: 2, 515). La basílica se inscribe espacialmente entre cuatro plazas, o sea, la del Obradoiro, la de las Platerías (en gallego, Pratarías), la de la Azabachería (en gallego, Acibechería) y la de la Quintana. También, por todos es sabido, la planta es de cruz latina, lo que no deja de ser un hexaedro en desarrollo. En cuanto a la planta del Pórtico de la Gloria (en gallego, Pórtico da Gloria), esta está dividida en tres tramos, de acuerdo con la distribución de la basílica en tres naves.

A mayores, habría que anotar que Rosalía refleja un curioso aspecto estético que estaría delatando su propia historicidad. Dice sobre la Catedral que "me pareció al mirarla que quería / sobre mi frente desplomar, ya en ruinas, / de sus torres la mole gigantesca" (Castro 1993: 2, 515), en donde advertimos un vestigio muy del gusto romántico, la obsesión por la muerte, en este caso, eclipsada por la presencia de las ruinas ${ }^{4}$. Si tenemos en cuenta una oportuna visión (gótica) de la Catedral, considerando que "es la ciudad dentro de la ciudad, el núcleo intelectual y moral de la colectividad, el corazón de la actividad pública, la apoteosis del pensamiento, del saber y del arte" (Fulcanelli 1993: 46), entonces estaremos encaminados hacia una posible lectura de estos versos en base a un sentir lírico de angustia existencial, de lo absurdo de vivir. Alguna voz crítica se ha manifestado en esta dirección, argumentando que "las tensiones estéticas producidas por su dialéctica estético-existencial facilitan, en cierto modo, la comprensión de su vida, su identidad y su poesía" (Guillon Barret 1986: 2, 487).

La cuarta edificación objeto de nuestro análisis es la iglesia de San Martín (en gallego, San Martiño). Este espacio abacial germina

${ }^{4}$ En este sentido, nótese que Rosalía publicó, en 1866, la novela titulada Ruinas. Desdichas de tres vidas ejemplares. 
en los versos, de una manera no declarada, a través de "el templo, / de fieles despoblado, y donde apenas / su resplandor las lámparas lanzaban" (Castro 1993: 2, 516). El edificio data del siglo XVI y su planta es de cruz latina, así que, de nuevo, estaríamos ante un hexaedro en desarrollo. La fachada está formada por tres cuerpos y tres calles, tratándose de un paño de piedra destinado a exaltar la figura de María y de la orden benedictina, como no podría ser de otro modo. Se distinguen, entre otras, las siluetas de san Benito, san Bernardo, san Gregorio Magno, san Pedro, san Pablo y la de un san Martín ecuestre que comparte su capa con un menesteroso.

\section{Estética tetraédrica de la luz}

La cuarta y última parte del poema "Santa Escolástica" resulta ser la expresión lírica del deambular anímico de la poeta a través de cuartetos de alejandrinos con rima asonante. Veamos algunas opiniones críticas que se han dado al respecto.

La entrada en este templo de San Martín, en el que se halla la representación de santa Escolástica, podría estar motivada por la necesidad de "encontrar alivio a sus males espirituales, a sus dudas, que aumentan la corriente amarga de su vida", dudas anímicas que quedarían solucionadas por medio de "la fe" (García Martí 1977: CXCIV).

Por su parte, las vacilaciones interiores de la voz lírica podrían resolverse o desvanecerse "ante una demostración estética de la existencia de la divinidad" (Carballo Calero 1958: 225). De tal forma, la imagen de santa Escolástica "le inspira, no ya un bello poema, sino una profunda vivencia religiosa" (Carballo Calero 1979: 146).

Igualmente podría interpretarse que "de la emoción estética se ha pasado a la emoción religiosa por un condicionamiento ambiental", al haber iluminado un rayo de luz la imagen de santa Escolástica, "produciendo en Rosalía una conmoción artístico-religiosa" (Mayoral 1974: 47).

Una perspectiva psicoanalítica permitiría, de manera análoga, explicar que el acceso al recinto de San Martín (en gallego, San Martiño), entendido como una entrada al "útero materno", establecería una situación "pre-edípica", viendo en las figuras de santa Escolástica y del ángel un medio por el que llegar al espacio maternal deseado en el fondo del inconsciente (Davies 1997).

Otra voz crítica prefiere hablar de dos actitudes de Rosalía ante lo religioso, "una actitud personal-psicológica que supone una previa y ardua crisis interior" y otra actitud "más objetiva", con la que la poeta podría tener "los ojos abiertos al exterior" y se explayaría "en la observación inteligente" (Nogales de Muñiz 1966: 119). Sería esta última la que se acomodaría a la ruta seguida por Rosalía en este poema. 
A todo ello cabría añadirle otra panorámica, la relativa a ver en la iglesia de San Martín una imagen tradicional y universal, "la mándala, el espacio cerrado representativo del cosmos, presidido por la Divinidad, propicio a la meditación, a la experiencia espiritual" (Navas Ruiz 2008).

Conforme a todo lo expuesto, semeja interesante la consideración de varias cuestiones. Los cuatro primeros cuartetos de esta cuarta parte de "Santa Escolástica" nos ubican en el espacio arquitectónico interior de San Martín; la poeta parece estar situada bajo "las anchas bóvedas", conmovida por un "silencio místico / que llenaba el espacio de indefinidas notas" (Castro 1993: 2, 517). Sensorialmente se van produciendo reacciones del exterior a su interior, oyendo notas "tan sólo perceptibles al conturbado espíritu", oliendo "incienso y cera", y del interior al exterior también: "Y mi mirada inquieta, cual buscando refugio / para el alma, que sola luchaba entre tinieblas, / recorrió los altares". Finalmente "Suave, tibia, pálida la luz rasgó la bruma / y penetró en el templo" (Castro 1993: 2, 517), lo que supone, a las claras, una variación de la descripción estética de la que contempla, en este caso, la poeta. A partir de este momento estético, "iYa yo no estaba sola!" y "en un nimbo envolvía vago el sol de la tarde" (Castro 1993: 2, 518), antítesis de "llovizna triste humedecía en silencio / de las desiertas calles las baldosas" (Castro 1993: 2, 514), por ejemplo.

Decía el crítico Xosé Filgueira Valverde que Rosalía, tal vez, compartía el mismo estado de soledad al que está condenado el genio, algo que estaría acercándola, sin ir más lejos, al francés Alfred de Vigny (1797-1863), para quien "só o silencio é grande. E todo o demáis é feble" (Filgueira Valverde 1989: 51). Mas tampoco omitía que la fuerza semántica del silencio en este poema de Rosalía podría encajar en la misma línea que actúa la "soledad sonora" en el Cántico espiritual del místico abulense san Juan de la Cruz (1542-1591).

De tal guisa, no parece desproporcionado intuir a la eximia poeta compostelana en el uso lírico de algunas fórmulas místicas estereotipadas, casi idénticas a las manejadas por el conocido como santo de Ávila; así, por ejemplo, "me deslicé cual corza fugitiva" (Castro 1993: 2, 515), frente a "Como el ciervo huiste" (Cruz 1968: 15); "Bajo las anchas bóvedas" o "cual resuena en la gruta" (Castro 1993: 2, 517), frente a "subidas cavernas de la piedra" (Cruz 1968: 23)"; "el fuego del amor puro y santo" o "me hirió calladamente, como hiere los ojos / cegados por la noche la blanca luz del alba" (Castro: 1993: 2, 518), frente a "iOh llama de amor viva, / que tiernamente hieres / de mi alma en el más profundo centro!" (Cruz 1968: 37); "iCementerio de vivos!" (Castro 1993: 2, 514), frente a "Vivo sin vivir en mí, / y de tal manera espero, / que muero porque no muero" (Cruz 1968: 42). 
En esta línea expositiva habría que tener en cuenta la presencia del lugar común del ubi sunt? en el primer sexteto de la segunda parte del poema, "¿Es verdad que hubo aquí nombres famosos, / guerreros indomables, grandes almas? / ¿Dónde hoy su raza varonil alienta?" (Castro 1993: 2, 514), pues podría estar reflejando también un cliché propio del ascetismo, en concreto, el relativo a la vanidad de la existencia humana y el desmoronamiento de su mundo de valores.

\section{Conclusiones}

Con todo lo revelado, semeja viable mostrar ya alguna deducción acerca de la presencia estética espacial de algún sólido geométrico en diversos edificios compostelanos, además de percibir cierta coincidencia numérica en el transcurro poético de "Santa Escolástica" ${ }^{5}$. En cuanto a su forma, este poema se distribuye numéricamente en torno al número cuatro, siendo cuatro sus partes. En la sección cuarta, el tipo de estrofa elegido por la escritora es el cuarteto. Se ha visto, de igual manera, que uno de los sólidos platónicos es el tetraedro ${ }^{6}$, el cual tiene cuatro caras y cuatro vértices. También decíamos que cada cara de un tetraedro tiene forma de triángulo; la portada del Hospital Real está formada por tres cuerpos, la planta del Pórtico de la Gloria está dividida en tres tramos, en proporción y armonía con la distribución de la planta de cruz latina de la Catedral, esta con tres naves en el brazo longitudinal. En lo que concierne a la iglesia de San Martín, su planta es de cruz latina con tres naves, mientras que su fachada está constituida por tres cuerpos y tres calles.

En términos similares, la presencia estética del hexaedro no deja lugar a dudas, ya que se ha podido apreciar la forma cúbica definitiva o en desarrollo, en el caso de la cruz latina- que tienen cuatro de los principales edificios objeto de nuestra observación, esto es, el Colegio de Fonseca, el Hospital Real, la Catedral y la iglesia de San Martín. Este sólido tiene seis caras, y la mayor parte de las estrofas de las secciones I, II y III de "Santa Escolástica" son sextetos. Asimismo cada cara de un hexaedro o cubo forma un cuadrado. El cuadrado de cuatro es dieciséis, y del siglo XVI son

\footnotetext{
${ }^{5}$ En cuanto a la cronología, resulta llamativo que el itinerario realizado por la poeta sea en el mes de abril, por tanto, el cuarto mes del año. Además, la acción lírica sucede por la tarde, o sea, en la tercera parte del día.

${ }^{6}$ Poligonalmente, cada cara de un tetraedro es un triángulo equilátero. Rosalía, en un momento de su trayecto lírico, se refiere espacialmente a "donde atrevida se destaca / del Cebedeo la celeste imagen" (Castro 1993: 2, 515), en clara alusión al frontispicio del palacio de Rajoy (en gallego, Raxoi), dedicado a la batalla de Clavijo, coronado por una figura ecuestre del apóstol Santiago, curiosamente, también obra de José Ferreiro. Este remate superior de la fachada tiene forma triangular.
} 
todos los edificios interpretados en sus versiones estéticas del espacio, como también en el siglo XVI se desarrollaron las vidas de dos de los místicos españoles aludidos, santa Teresa de Jesús y san Juan de la Cruz.

Y hablando de cruz, esta representa los cuatro elementos de la antigüedad. En su texto Timeo, Platón reflexionaba acerca de estos principios cosmogónicos que "existían por virtud de la necesidad, y el Artífice de lo mejor y más bello, que existe, tomó estos elementos de entre las cosas que devienen ó tienen comienzo, cuando engendró el dios que se basta a sí mismo, porque es perfecto" (Platón 1872: 226).

De tal forma, a ambas estéticas comentadas, hexaédrica y tetraédrica, les corresponderían dos de los cuatro elementos; al elemento tierra se le asignaría la figura cúbica, pues es el "más noble de los cuatro cuerpos y el más capaz de recibir una forma determinada; y estas cualidades suponen en el cuerpo que las tiene, las bases más firmes" (Platón 1872: 204). Asimismo al sólido tetraedro se le relacionaría con el elemento fuego, puesto que "conforme á lo que dictan la recta razón y la probabilidad, que el sólido, que tiene la forma de una pirámide, es el elemento y el germen del fuego" (Platón 1872: 205).

Parece ser que el tetraedro suele ser símbolo del amor y de la conexión con el Ser superior, mientras que el hexaedro estaría relacionado con la conexión de la vida con la naturaleza (Cirlot 1997). En este sentido, baste traer a estas líneas la opinión al respecto de François Chateaubriand, convencido de que "los bosques han sido los primeros templos de la Divinidad, y en ellos tomaron los hombres la primera idea de la arquitectura" (Chateaubriand 1852: 155).

Por otra parte, Rosalía concluye su deambular anímico por la denominada estética de la luz, no sin antes deducir, convencerse y exclamar que "iHay arte! iHay poesía...! Debe haber cielo. iHay Dios!" (Castro 1993: 2, 518). Por todo lo visto, no sería muy dispar, ni mucho menos, llegar a la conclusión de que la poeta semeja inferir y aceptar la existencia de una belleza física -iHay arte! $-{ }^{7}$, de una belleza espiritual -iHay poesía!- y de una belleza ideal -iHay Dios!.

De nuevo, los presupuestos filosóficos platónicos, en este caso de El banquete, se adaptarían perfectamente a esta situación interpretativa:

7 Se cree que el escritor francés Henri Beyle (1783-1842), conocido por el seudónimo de Stendhal, experimentó un curioso fenómeno en una visita a la florentina basílica de Santa Croce. La exposición a una o varias obras de arte de gran belleza parece ser la responsable de una o varias alteraciones físicas en el individuo que las contempla, pudiendo padecer alucinaciones, entre otras. Nótese que la ciudad de Florencia fue cuna del esplendor renacentista. 
Pero entre todas las ciencias hay una que cultiva por completo toda su alma, y es la ciencia misma de lo bello, cuyo conocimiento es el colmo y la perfección del amor. ¿Y qué es esto tan bello, tan codiciable y tan difícil de alcanzar? Es la belleza en sí, eterna y divina, la única belleza real de la que todas las otras son solo un mero reflejo. Iluminado por su luz pura inalterable, hombre afortunado entre muchos a quienes les es dado contemplarlo al fin, siente nacer en él y engendrar en los otros toda clase de virtudes; este hombre es verdaderamente dichoso y verdaderamente inmortal. (Platón 1871: 358)

Desde la perspectiva expuesta, coincidimos con la opinión del crítico Ricardo Navas al indicar que "Rosalía descubre en Santa Escolástica la serenidad, la paz espiritual, la ecuación platónica de belleza y divinidad. El arte reafirma la existencia de Dios. Las dudas de la poeta desaparecen" (Navas Ruiz 2008).

Bien es cierto que a la cuarta parte de "Santa Escolástica" le preceden tres secciones, en las que los juicios estéticos realizados por la voz lírica sobre determinados edificios contribuyen a crear una atmósfera de lo artístico, de deleite espiritual. Así, los relieves de la puerta de Fonseca los percibe como cuidados y delicados, mientras que la fachada, en general, la advierte como esbelta, flexible y, sobre todo, que no emite el sonido que le sería propio, entrando en perfecta armonía con su silencio. Por su parte, el Hospital Real parece concebirlo como una obra con mucha dignidad. La Catedral y los arcos románicos del Pórtico de la Gloria los intuye próximos a la bizarría, tal vez, lúcidos y espléndidos.

En otro orden de cosas, semeja apropiado igualmente mostrar alguna conclusión a la que hemos llegado, después de emplear un criterio de observación del texto lírico "Santa Escolástica" desde la óptica que da título a uno de nuestros epígrafes, es decir, la estética de la luz, también conocida como metafísica de la luz o teología de la luz.

En su momento, se han aducido algunas concomitancias entre este poema de Rosalía y algunos textos de san Juan de la Cruz. Valga decir, como refuerzo a nuestro razonamiento, que la escritora compostelana ya realizaba guiños literarios a santa Teresa de Jesús (1515-1582) en el prólogo de su primera novela, La hija del mar, publicada en 1859, refiriéndose a ella como "ese espíritu ardiente cuya mirada penetró en los más intrincados laberintos de la teología mística" (Castro 1993: 1, 47). En este texto narrativo, tampoco se olvidaba de san Juan de la Cruz, incluyendo una cita de él en el capítulo VII, titulado, muy apropiadamente, "La tormenta": Gocémonos, amado: / y vámonos a ver en tu hermosura / al monte o al collado / do mana el agua pura, / entremos más adentro en la 
espesura" (Castro 1993: 1, 90). Por tanto, este tipo de cuestiones tienen cierta continuidad en el tiempo literario de Rosalía.

El poeta, al igual que el místico, busca en la simbólica oscuridad lo que no crea en sí mismo, recibiendo una iluminación que le hace comprender, de manera intuitiva, pero no analítica, una realidad que está oculta para la mayoría (Maritain 1955). Eso sí, la dificultad vendría a la hora de trasladar esa experiencia al arte, lo que explicaría la solución final que da Rosalía, al emplear los puntos suspensivos: "iHay poesía...!" (Castro 1993: 2, 518).

Por todo lo visto, el gran esteta de Compostela, Ramón Otero Pedrayo, estaba muy acertado al escribir sobre la dificultad que entraña la interpretación de la ciudad, al referirse a que son "precisos longos cursos de soidades e silencios" (Otero Pedrayo 2000: 46).

\section{Bibliografía}

BOUZA ÁLVAREZ, Fermín (1972): "El escultor José Ferreiro en Camariñas". Compostellanum, vol. 17, núms. 1-4, pp. 277-288.

BOUZA BREY, Fermín (1962): "Adriano y Valentina, motivaciones inspiradoras de Rosalía de Castro". Cuadernos de Estudios Gallegos, núm. 53, pp. 374-390.

CARBALLO CALERO, Ricardo (1958): "Visión de la vida en la lírica de Rosalía de Castro". Cuadernos de Estudios Gallegos, núm. 40, pp. 209-241.

- (1979): Estudos rosalianos. Aspectos da vida e da obra de Rosalía de Castro. Vigo: Galaxia.

CASTRO, Rosalía de (1993): Obras completas de Rosalía de Castro. Edición de Marina Mayoral. Madrid: Turner, 2 vols.

CIRLOT, Juan Eduardo (1997): Diccionario de símbolos. Madrid: Siruela.

CHATEAUBRIAND, François-René (1852): Genio del cristianismo ó bellezas de la religión cristiana. Traducción de Torcuato Torio de la Riva. Méjico: Imprenta de Juan R. Navarro, editor.

CRUZ, San Juan de la (1968): Poesías completas de San Juan de la Cruz. Edición de Dámaso Alonso. Madrid: Aguilar.

DAVIES, Catherine (1997): "O retorno á nai catedral, unha estranxeira en terra de ninguén: Rosalía de Castro a través de Julia Kristeva". Grial, núm. 133, pp. 503-525.

FILGUEIRA VALVERDE, Xosé (1989): "O silencio en Rosalía", en Quinto Adral, pp. 49-51. Sada: Do Castro.

FULCANELLI (1993): El misterio de las catedrales. Barcelona: Plaza \& Janés.

GARCÍA MARTÍ, Victoriano (1977): "Rosalía de Castro o el dolor de vivir", en Obras completas de Rosalía de Castro, vol. 1. Madrid: Aguilar.

GARCÍA VEGA, Lucía (2011): "Rosalía de Castro agonista. Diálogo protagonista y antagonista con la ciudad de Santiago de Compostela" [en línea]. Ángulo Recto. Revista de estudios sobre la ciudad como espacio plural, vol. 3, núm. 2, pp. 51-67. En: http://www.ucm.es/info/angulo/volumen/Volumen03-

2/articulos04.htm Doi: http://dx.doi.org/10.5209/rev ANRE.2011.v3.n2.37579 [Consulta: 22/08/2014]. 
GUILLON BARRETT, Yvonne (1986): "Dionisio y Apolo: aproximaciones nietzscheanas a la dialéctica estético-existencial de Rosalía de Castro", en Actas do Congreso internacional de estudios sobre Rosalía de Castro e o seu tempo (Santiago de Compostela, 15-20 de julio de 1985), vol. II, pp. 481-487. Santiago de Compostela: Consello da Cultura Galega / Universidade de Santiago de Compostela.

LÓPEZ VÁZQUEZ, José Manuel (1990): "Retablo de Santa Escolástica", en Galicia no tempo. Catálogo da exposición celebrada no Mosteiro de San Martiño Pinario, pp. 335-336. Santiago de Compostela: Arcebispado, Diócesis de Galicia / Xunta de Galicia, Dirección Xeral do Patrimonio Histórico e Documental.

- (2009): "A propósito del retablo mayor de la Magdalena de Montemaior (1773): Algunas esculturas inéditas de José Ferreiro". Compostellanum, vol. 54, núms. 3-4, pp. 487-506.

MARITAIN, Jacques (1955): La poesía y el arte. Buenos Aires: Emecé.

MAYORAL, Marina (1974): La poesía de Rosalía de Castro. Madrid: Gredos.

NAVAS RUIZ, Ricardo (2008): Rosalía y Zorrilla: una tarde, una iglesia, una duda. Alicante: Biblioteca Virtual Miguel de Cervantes.

NOGALES DE MUÑIZ, María Antonia (1966): Irradiación de Rosalía de Castro. Palabra viva, tradicional y precursora. Barcelona: Talleres Gráficos Ángel Estrada.

OTERO PEDRAYO, Ramón (2000): O espello no serán. Vigo: Galaxia. PICAUD, Aimeric (2004): El libro del jacobeo. Madrid: Encuentro. PLATÓN (1871): "El banquete", en Obras completas de Platón, vol. V. Edición de Patricio de Azcárate. Madrid: Medina y Navarro Editores.

- (1872): "Timeo", en Obras completas de Platón, vol. VI. Edición de Patricio de Azcárate. Madrid: Medina y Navarro Editores.

RODRÍGUEZ, Francisco (2011): Rosalía de Castro, estranxeira na súa patria. (A persoa e a obra de onte e hoxe). A Coruña: Asociación SocioPedagóxica Galega. 